\title{
Discussion on the Mechanical Drawing Teaching for Talent Cultivation of Utility Model
}

\author{
Hua Chen \\ School of Mechanical Engineering \\ University of Science and Technology Beijing \\ Beijing, China 100083
}

\author{
Tong Cao \\ School of Mechanical Engineering \\ University of Science and Technology Beijing \\ Beijing, China 100083
}

\author{
Guanghui Yang \\ School of Mechanical Engineering \\ University of Science and Technology Beijing \\ Beijing, China 100083
}

\begin{abstract}
In order to cultivate talents of virtue and ability and all-round development, the teaching system of mechanical drawing is deeply studied and practiced, so as to establish scientific and rational curriculum architecture intended for the grasping of the basic theories, basic knowledge, basic methods and basic skills. It is intended that the students learn basic theories in the Mechanical Drawing AI course, grasp basic knowledge in the Mechanical Drawing AII course, strengthen the grasping of the basic methods through the practice of disassembly and mapping, and improve basic skills through freehand, instrumental and computer drawing. Through optimizing classroom teaching, the hands-on practical teaching that takes disassembly and mapping and computer practice as the main methods is carried out, and the mode of learning through racing featuring the main forms of competition and authentication is developed, so as to enhance teaching effectiveness.
\end{abstract}

Keywords—mechanical drawing; curriculum system; practical teaching

\section{INTRODUCTION}

The development level of higher education is an important symbol of national development level and development potential. China's higher education shoulders the important task of cultivating the builders and successors of socialist cause who have all-round development in morality, intelligence, physique and aesthetics. The CPC Central Committee has made a strategic decision to speed up the construction of world-class universities and first-class disciplines, which is intended to improve the development level of China's higher education and enhance the core competitiveness of the country $[1,2]$. In line with the spirit that the function of each course shall be fully developed, the mechanical drawing teaching team of Beijing Science and Technology University has actively explored the teaching methods of education, optimized the curriculum system, and

Fund project: Education and teaching reform and research project in 2014 of University of Science and Technology Beijing (JG2014M22). made continuous reform and innovation on key issues such as teaching content and teaching links [3].

\section{OPTIMIZE THE DESIGN OF TEACHING CONTENT}

The mechanical drawing course is the primary course to train students' primary cognitive ability in mechanical specialty. How to make students have a clear definition of professional knowledge on the basis of not having too many professional courses in the first year of college, and keep a keen interest in the future professional study, is the primary task of the mechanical drawing course.

In order to cultivate talents of virtue and ability and allround development, a scientific and rational curriculum architecture guided by the basic theories, basic knowledge, basic methods and basic skills was established [4]. The mechanical drawing course system offers courses of Mechanical Drawing AI, Mechanical Drawing AII and computer practice teaching, by optimizing teaching content, designing teaching methods and organizing students to participate in national competitions, CAD skill certification, scientific and technological innovation projects, etc, to test the teaching effect and promote the teaching reform, so as to achieve the teaching goal of talent cultivation of utility model.

\section{A. Learn the Basic Theories through the Mechanical \\ Drawing AI}

The engineering drawing is formed by combining geometry with engineering application and engineering specification. As an important part of engineering drawing, mechanical drawing is a basic compulsory course for mechanical and related majors in most colleges and universities. The Mechanical Drawing AI course of 48 credit hours of Beijing Science and Technology University opens up in the first semester of the freshman year, which offers the basic theories of the mechanical drawing, and studies the composition and expression of the geometric forms based on geometry, projection method and basic engineering standard. The key learning points of this course are the basic principles 
and properties of the point, line and surface orthographic projection, the drawing, reading and dimensioning of the combination views, the drawing expression method of the equipment apparatuses, and the principle and method of drawing axonometric drawings and so on. The course can effectively cultivate students' spatial imagination ability and abilities to analyze problems and illustrate the geometric problems of general spaces, and by studying the basic principle of the orthographic projection and its application, the students can develop the ability to correctly, completely, clearly and rationally express the equipment apparatuses [5, 6], which lays a solid foundation for developing the students' ability to skillfully and accurately draw standard and qualified mechanical drawing and ability to read and understand the mechanical drawing correctly.

\section{B. Learn the Basic Knowledge through the Mechanical Drawing AII}

The engineering drawing is an essential tool for engineering technical personnel to express and exchange technical ideas, as well as an important technical document to guide works such as production, construction and management, etc. The course of Mechanical Drawing AII has 48 credit hours, which is opened in the second semester of the freshman year. Based on the basic theories offered in Mechanical Drawing AI, this course is intended to make the students learn the basic knowledge of the mechanical drawing and grasp the relevant regulations in the national standard of Mechanical Drawing and Technical Drawing, so as to develop the ability to draw and read mechanical drawings. It also lays the necessary foundation for the study of relevant follow-up courses, curriculum design and graduation design. The course is intended to cultivate students' habit to consciously abide by the basic provisions of national standard, cultivate their graphic expression ability to use all kinds of expression methods stipulated in various national standards to conceive, analyze and express engineering issues, and cultivate and develop their spatial thinking and image thinking ability as well as patient and meticulous working style and rigorous and serious working attitude.

\section{Consolidate the Basic Methods through the Practice of Disassembly and Mapping}

The integrated practice of component disassembly and mapping is an important practical teaching link to consolidate the basic methods of drawing expression, which is a comprehensive test and reinforcement for the students' learned contents in the engineering drawing course. In order to grasp the basic methods of drawing and reading mechanical drawings, the students are offered component disassembly and mapping practice which is interspersed in the process of learning the expression methods of machinery, components and spare parts and the relevant national standards. Through the practice of component disassembly and mapping, students can have an intuitive understanding of various components of the assembly, and understand the working principle and assembly relationships among the components, make clear disassembly and assembly sequence and component processing technology, have a deeper understanding and improvement of the dimensioning and annotating "technical requirements" on the drawings, and enhance the design concept. And preliminarily establish engineering consciousness, standard consciousness, quality consciousness and safety consciousness, improve the practical ability, strengthen the collaboration awareness, and cultivate rigorous, realistic, serious and responsible engineering attainment, so as to lay a solid foundation for the actual work.

\section{Improve the Basic Skills through Freehand, Instrument and Computer Drawing}

The students of the mechanical major are trained in basic skills all the time while learning cartographic theoretical knowledge. The teaching of freehand drawing as well as instrument and computer drawings run through the courses of Mechanical Drawing AI and Mechanical Drawing AII, and as the teaching process goes on, the corresponding freehand drawing exercises and computer teaching practice are arranged to facilitate the improvement of the students' basic skills. After learning the basic theories and basic knowledge of drawing, the disassembly and mapping practice link was arranged, the training of freehand sketching and instrument-assisted mechanical drawing are strengthened, and the computer drawing exercises are added. In this way, the students can not only complete the study tasks of component disassembly and mapping, but also perform the training of inter-conversion between the three-dimensional modeling and two-dimensional drawing, thus promoting the improvement of the students' thinking ability of configuration and improving their spatial imagination ability. The organic integration of traditional and modern drawing techniques enables students to better understand the importance of traditional freehand and instrumental drawing, and correctly understand the advanced role of the computer drawing.

\section{SCIENTIFIC IMPLEMENTATION OF PRACTICAL TEACHING}

\section{A. To Attach Importance to the Practice Process of Disassembly and Mapping}

Mapping of parts is the important part of Mechanical Drawing AII course, the practical teaching link of consolidating students' knowledge of mechanical drawing, strengthening engineering training and enhancing engineering consciousness. To further improve students' ability to draw and read mechanical drawings through component mapping and strengthen the skill of using computer to draw mechanical drawing. It is very important to cultivate students' practical ability, knowledge application ability, problem analysis and problem solving ability. Disassembly and assembly of parts and practice of surveying and mapping were arranged two times in teaching.

1) Topic 1: disassembly and mapping of vise parts: We have arranged the students to carry out the dismantling and mapping practice of the vise parts after learning the basic concept of components and the drawing of engineering drawing and reading relevant knowledge. The vise parts are shown in "Fig.1". A group of three students unpacked a piece of the vise, and mapped the main parts, such as the palm and 
base. Draw the parts drawing according to the drawing of the parts, and draw the assembly drawing of the vise with the parts drawing of the other parts. Draw 2D engineering drawings of parts with computer and build 3D model.

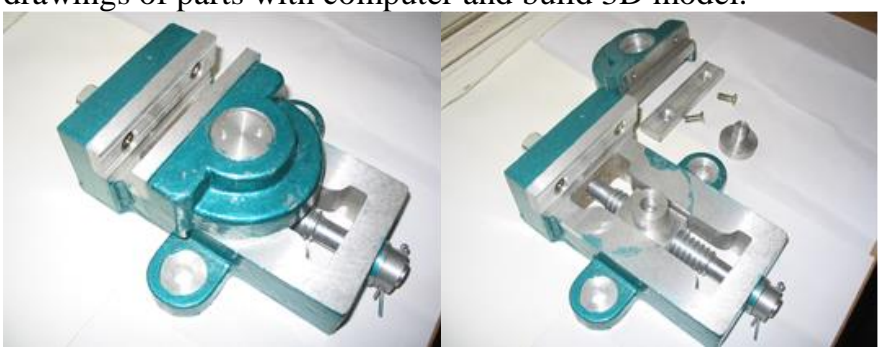

Fig. 1. Vise parts.

2) Topic 2: disassembly and mapping of gear oil pump components: We have arranged the students to carry out the gear oil pump parts dismantling and surveying and mapping practice after all the knowledge points of the mechanical drawing course are completed. Gear oil pump components shown in "Fig. 2". A group of three students disassembled a gear oil pump in physical parts, and surveyed the pump cover, pump body, pump seat three parts. To draw parts drawing with ruler gauge according to parts mapping drawing and draw the assembly drawing of gear pump combined with the parts drawing of other parts. To draw 2D engineering drawing with computer drawing software, establish part model and generate assembly animation.

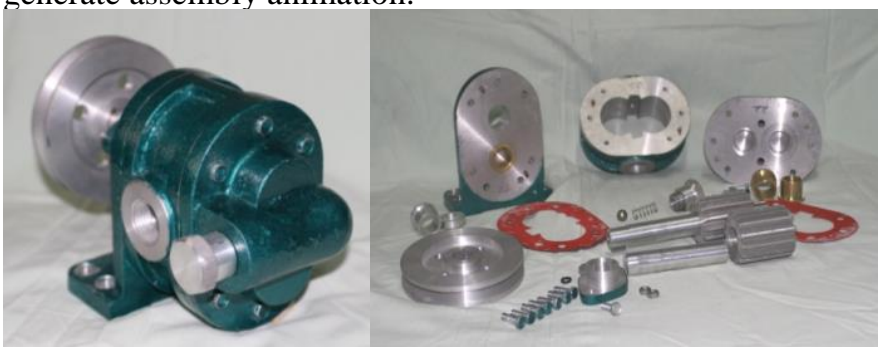

Fig. 2. Gear oil pump parts.

After completion of the gear oil pump disassembling and mapping operation, the first defense will be conducted. The defense is based on gear oil pump to investigate students' knowledge about mechanical drawing course such as the concept and relationship of parts, parts drawing, assembly drawing, etc. The defense will adopt a one-to-one approach. Students will randomly select question or questioned by the answer teacher and students will answer question orally. The purpose of defense is to examine each student's understanding and mastery of gear pump surveying and mapping practice and evaluate students' ability to apply the relevant knowledge flexibly and solve practical problems

After learning all the knowledge points of engineering drawing course, a comprehensive and systematic engineering training for students will be carried out. This will be beneficial for students to digest what they have learned and to consolidate and improve. The ability of students to independently analyze problems in engineering surveying and mapping and the ability to express complex components and parts will be developed. The team spirit and rigorous learning attitude and work style of students will be strengthened.

\section{B. Strengthen Computer Practice Teaching}

The application of computer graphics software greatly promotes the study of mechanical drawing courses with the increasing popularization of computer technology. Compared with manual drawing, computer drawing is an efficient and high-quality drawing technique. Computer practice teaching after the completion of Mechanical Drawing $A I$ and Mechanical Drawing AII courses especially greatly promotes the mastery of cartographic knowledge and the improvement of computer drawing ability, lays a good foundation for the follow-up study of professional courses and the production practice of future students to go to post.

Computer practice contains 20 credit hours. The topic is divided into two forms: Modeling and drawing and students can choose one of them. The modeling topic gives the parts drawings of all parts in the assembly. The 3D model of each part will be established by using inventor software, and the explosion graph will be assembled and generated; The assembly drawing of assembly will be given by the map reading title. Imagine the shape of each part after understanding the assembly drawing. The 3D model of each part is established by using the inventor software and the explosion diagrams will be assembled and generated.

The students will carry out the training of the mutual conversion between the 3D modeling and the two-dimensional drawing through the practice of computer practice after the end of mechanical drawing course to promote the improvement of thinking ability of configuration and so as to improve students' spatial imagination ability. The process of computer practice is also the consolidation and improvement of the mechanical drawing course. Review the relevant knowledge of mechanical drawing will promote students to further grasp the basic course of mechanical drawing through two forms about modeling and understanding to exercise.

\section{DEVELOPMENT OF THE TEACHING MODEL OF PROMOTING LEARNING BY COMPETITION}

\section{A. Competition Program for National College Students}

To organize students to participate in various competitions and innovative design activities at all levels actively in order to promote learning and strengthen exchanges. University of Science and Technology Beijing has organized students to participate in the National College Students' advanced mapping technology and product information modeling innovation contest for seven years and achieved very good results. Every year, the school holds an intramural tryout to call for all students to participate in order to select excellent students to participate in the competition. The students responded warmly and influenced extensively, which promoted the study of drawing course.

The project team teachers actively lead students to participate in the National University machinery innovation design competition to cultivate the ability of preliminary 
product innovation design and basic engineering consciousness. At the same time, teachers and students broaden their horizons, expand exchanges, and promote learning through competition. Regularly organize students to participate in the National Computer Aided Technology Application Engineer CAD certification organized by the Ministry of education and the China Society of graphics every year to improving students' professional basic skills and engineering technology ability.

\section{B. A Variety of Competition Activities in Class}

Create a variety of competitive activities independently. Through competition to strengthen learning and improve skills in addition to encouraging students to participate in various competitions organized by national and school organizations. The following are two kinds of contests that combine the content of a drawing course to a podium.

1) The handwriting competition of technical lettering: Technical lettering practice is an important content of drawing course. Carry out an engineering word contest after teaching the relevant knowledge and writing requirements of technical lettering in order to improve students' writing skills and stimulate students' interest. The competition content is the imitation work of technical lettering on the exercise book. Next class, excellent homework should be commended, rewarded and displayed. The selection and recognition of excellent assignments should be completed by students who will announce the award process, announce the award-winning work and award. The technical lettering competition organized by students has greatly aroused students' enthusiasm. The students' thinking is active, and the way to show the prize work and award is varied, so that the classroom is full of vigor and the enthusiasm of learning is improved.

2) Hand drawing exercises of axonometric drawing: The axial projection image has a strong sense of stereoscopic image, which is more intuitive and has more application in engineering technology and other disciplines. Therefore it is a main content in engineering drawing teaching to draw the axis mapping correctly. Freehand drawing is a design method frequently used in product design front end. It is also the basic skill that engineers and technicians should possess. Arrange the assignment of freehand axonometric drawing after teaching the axonometric drawing and the knowledge of freehand drawing. The job content is to select an object to be seen in the life, and draw its axonometric drawing on A4 paper by hand. Next class, excellent homework should be commended, rewarded and displayed. Excellent homework selection will be completed by students and teachers together. First of all, each class consists of two classes representing students to choose better assignments and then the teacher and the class representatives will give a certain amount of good work together. In the next class, the student representatives will introduce the selection methods of outstanding assignments to the students, and show the excellent assignments and awards. Students should pay attention to the objects in life and choose the objects familiar in their life such as mobile phones, lamps, water bottles, mineral water bottles and so on. The object will be expressed by using the knowledge of axonometric drawing and hand drawing skills in class. The knowledge that is learned will be used flexibly in life.

\section{CONCLUSION}

The teaching team of "mechanical drawing" course in University of Science and Technology Beijing has been trying to explore the "Trinity" training model of value shaping, ability training and knowledge imparting, establish a mechanical drawing course system under the guidance of basic theories, basic knowledge, basic methods and basic skills and innovate education methods, enhance the effectiveness of education, and cultivate the talents of all-round development for utility model constantly.

\section{REFERENCES}

[1] Huang Yanhua. Research on training strategy of innovative talents in Universities. China educational technology equipment, 2015 (10): 61-62

[2] Lin Hai, Li Hong, Yuan Jianmei, etc. Theoretical and practical exploration of research oriented teaching in Universities. Journal of University of Science and Technology Beijing (Social Sciences Edition), 2013, 29(1): 94-99.

[3] Yang Huanghui, Cao Tong, Wan Jing, etc. Exploration and practice of new teaching mode of "Mechanical design drawing". Journal of graphics, 2013, 34(6): 114-117.

[4] Yang Huanghui, Chen Ping, Xu Qian, etc. Exploration and practice of teaching mode of modern engineering graphics. Journal of graphics, 2012, 33(Add): 28-30.

[5] Tian Ling, Tong Bingshu, Feng Juan. Research and practice of mechanical drawing new curriculum system. Journal of graphics, 2005, 26(5): 120-125.

[6] Han Liyan, Ding Qiao, Zhang Mengmei. Research and practice of teaching method for engineering drawing teaching content. Teaching research, 2012, 35(2): 76-78. 